\title{
The English Learning System Design Based on the Web Platform
}

\author{
Man Liu \\ Changchun Institute of Technology \\ CCIT \\ Changchun, China \\ E-mail: 339144089@qq.com
}

\begin{abstract}
With the rapid development of information technology in modern society to promote the informatization process, the world has accelerated the pace of modernization of education forward. Education technology has experienced from the traditional teaching, the common media technology to the computer technology and communication technology on the basis of the development of multimedia information network technology. This paper is to implement an English learning system based on Android platform. In this system, learning service provider can learn listening resources released by the server and system management work, which can satisfy English learning, learning, communication and other activities.
\end{abstract}

Keywords-English Learning System; Android Platform; Mobile Learning

\section{INTRODUCTION}

With the mature of mobile technology, language learning is gradually to the day-to-day work, advanced technology, combined with the characteristics of language learning, encourage the development of the mobile language learning, mobile learning English has become a modern important way of learning. According to the survey, English listening is still many students feel a weakness and difficulties. Traditional classroom teaching of listening learning to form gradually, in short, between people and students class time, less resources, could not guarantee the quality of listening teaching, causes students to get full voice edification and exercise [1]. Mobile smart phones in college students' group, however, has been popular, the use of mobile s mart phones as a learning carrier, overcome the limit of time and space, make up for a lack of resources, create heard environment anytime and anywhere, is beneficial to increase the chance of hearing, but also to improve the quality of the college students' English listening, to strengthen college students' English comprehensive ability to lay the foundation.

Mobile learning is based on digital learning on the basis of a new type of learning style, it has the mobility, high efficiency, such as broadcast, interactive, sharing, personalized learning characteristics. Android is an open source operating system based on the Linux kernel, is mainly used in smart phones, tablets and other mobile terminals. Using computer technology, wireless communication technology, multimedia technology and other modern technology to establish a mobile learning system, by running in an Android system of intelligent terminal equipment, can be used to supplement to the traditional learning mode powerful, for the majority of users provide personal learning support services anytime and anywhere [2]. The purpose of this paper is to implement an English mobile learning system based on Android platform. In this system, learning service provider can learn through the server-side resource distribution and system management work; learn the service recipient by installing the mobile client to Android mobile devices, can live course learning, learning, communication and so on.

Web-based teaching system or study system at home and abroad exist the defects in the design of learners' autonomous learning and active learning support. Thus it causes the effects of teaching and learning online is not ideal. Aiming at this situation, we put forward a new theory model of Web teaching System, which is the web-based learning Support System model.

\section{ANDROID MOBILE DEVELOPMENT TECHNOLOGY}

Android is a mobile operating system based on the Linux kernel, by Google and its Allies, the open handset alliance. Android smart phone operating system is based on the Linux kernel, the Android system is composed of four parts. The top is application software, directly facing the user. And then the developer can call for interface display component, the third layer is the middle ware, it blocked the underlying operating system, the fourth floor is the Linux operating system kernel [3-4]. The Android operating system has the complete API and open nature, as shown in "Fig. 1".

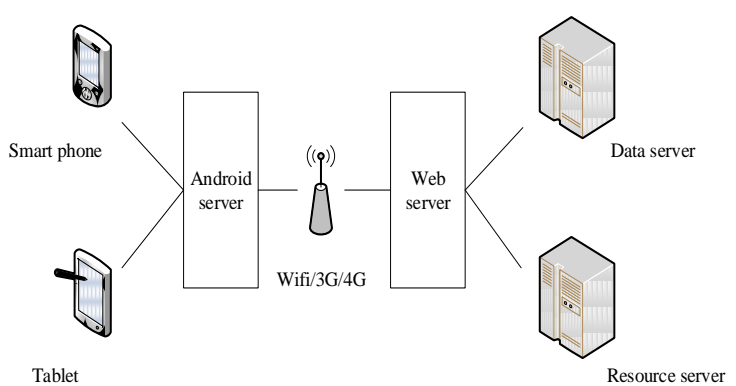

Fig. 1. Mobile learning system framework based on the Android plat form 
The client of mobile learning system mainly includes the Android smart phones and portable equipment such as Android tablets, users through their mobile devices to access courses and learning and other learning related operations. Mobile learning system of server-side main ly consists of two parts, the database server and server resources. Database server's main function is to store student related personal information, and is responsible for the validation and feedback the correctness of the users to submit personal information legitimacy. Server to manage the management course resources (hypertext, images, animation, streaming media, etc.) and handling online interactive information including student to ask the teacher answer questions, etc.

\section{FUNCTION DESIGN OF ENGLISH LEARNING SYSTEM BASED ON ANDROID}

Based on English learning Android system with the method of modular design. First of all, the learners use Android smart phone or tablet, mobile terminal equipment run the client program. After entering through the welcome screen, learners can conduct online course in communication, personal educational administration information management, online consulting, view school announcements, and other learning related activities [5]. English learning system Server adopts $\mathrm{B} / \mathrm{S}$ (Browser/Server and Browser/Server mode) structure of implementation, for the resource publishers, system admin istrators, mobile users of the client software for mobile learning related activities provides all kinds of basic services. The function of English learning system based on Android platform design module diagram is shown in "Fig. 2".

English learning system is based on the Android support for multiple devices. Client system configuration can be run on Android mobile phone, PDA, tablet computers and other portable devices. Updated listening resources for online and offline. Consider online update data traffic, can download learning resources to SD card in the PC, used to load the system. Online communication data flow is small, fast response speed. Client system configuration in the Android devices, the communication with the server using the Socket HTTP protocol, the communication data encapsulation as XML text. At the same time, the learning resources using a database to store, convenient for system data maintenance.

Web-based learning support system is a kind of teaching system, emphasizing on learners' learning as the center, creating a stimulating active learning environment for learners. In the process of learning, reasonable allocation of resources and the appropriate teaching strategy provide comprehensive support and help for learners' learning. Students complete the learning process mainly through selecting online courses and resources and answer to the teachers' questions. Web-based English learning support system starts from the needs of English learners, and is an integrated teaching system designed under the guidance of teaching design thought in the priority of learning. English learners learn English conveniently and easily in a musical environment by means of learning resources and tools provided by a number of teachers.

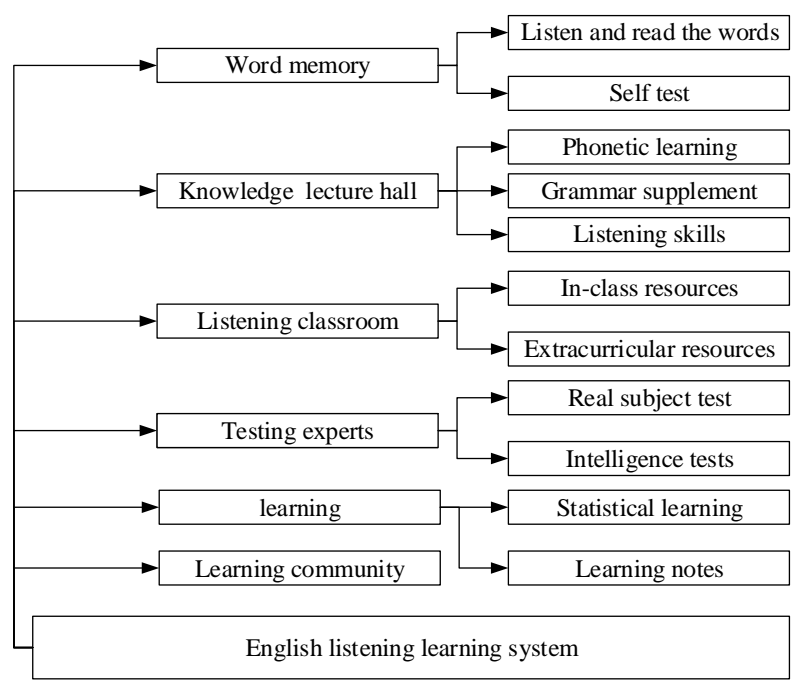

Fig. 2. Function module of English learning system based on Android

\section{THE DEVELOPMENT OF ENGLISH LEARNING SYSTEM BASED ON ANDROID}

According to the potential user demand survey and content design principles, the final design of Eng lish learning system based on Android design process is shown in "Fig. 3".

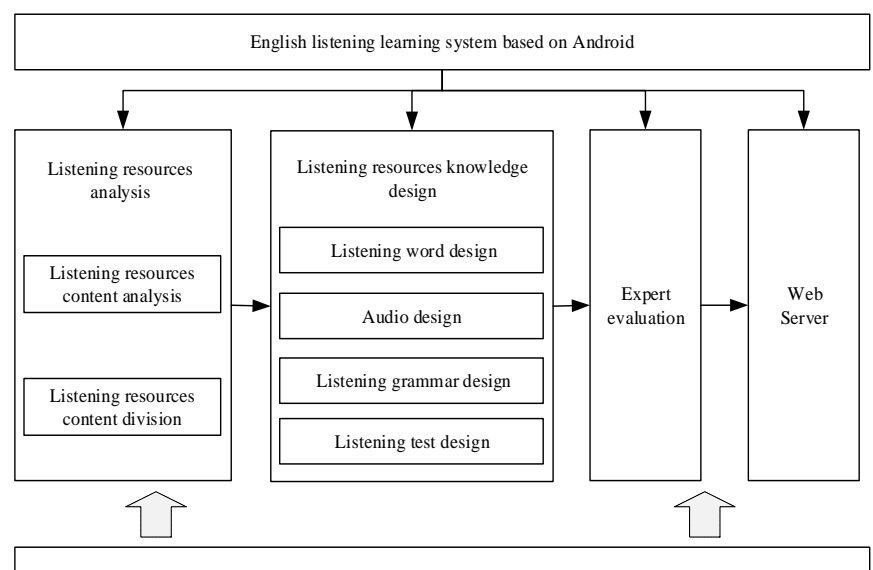

Using the Android development tools to design and develop the listening learning resources

Fig. 3. The development of English learning system based on Android

The study of English learning system design principles, the first consideration is positioning of the system rationalization, in the first line of user demand survey content is in potential users, ask is need a lot of learning content and learning content of small and exquisite. Obviously, the choice of the user does not want to be an encyclopedia of mobile learning platform. When set up mobile learning system, therefore, it must first be clear that who is the service object in the system, the system for the user needs to provide what aspects of learning content. Due to the principle of index system is set up mobile learning content is important basis of evaluation standards, thus determine the indicators of mobile learning content design, is 
the foundation of the mobile platform design. The scheme through prototype design scheme, design a prototype first, and through constant selection, refactoring, gradually improve the design of the knowledge of mobile learning platform, eventually form contains words, audio, video, images and other content, knowledge point segmentation good English learning platform. In this paper, in the design of the prototype of the due time is limited, only the content of design work, the final result is stored in the MYSQL database.

\section{CONSIDERATION AND IMPROVEMENT OF WEB-BASED ENGLISH LEARNING SUPPORT SYSTEM}

Building learning environment close to the reality and transcend it, paying attention to the development of selflearning habit and ability. The meaning of design and development of Web-based learning support system is breaking the traditional teaching mode and using the advanced multimedia network technology on the basis of the advanced education theory to create adaptable learning and educational environment for the learner's personalized autonomous learning, and provide a full range of support for online learning, which helps learners to achieve learning goals. The final goal is to cultivate autonomous learning habit and ability of independent learning through the learning activities under the network environment. The core of Web-based English learning support system is dynamic adaptability of different learners; the key is the intelligent choice of learning strategies and learning strategy to organize the implementation.

Web-based English learning support system must establish policy database, repository, and basic information database, offer a variety of interactive methods, fully collect user information (such as age, educational background, professional, preferences etc.). It learns the user's knowledge, ability and learning objectives through diagnostic evaluation; monitors the individual learning process through the log and access records, communication records and obtains user's data to carry on the comprehensive analysis, finds out the intrinsic characteristics, and then choose matching learning strategy, adjust the corresponding learning function and allocate resources, form a optimal learning environment to every individual, and guide students in the correct way and method to carry out the learning activities.

It is based on $3 \mathrm{G}$ technology and the application of mobile learning mode analysis and related functional module analysis, after the English mobile learning system by Nokia S60 mobile phones for the client platform, through internal encapsulated URL request to the server for corresponding operation. The system mainly includes two parts: mobile client and web server.

English mobile learning system adopt B/S/S three layer model as system architecture, as shown in figure 4. Display layer is divided into background management system and mobile terminal English learning system two parts, the mobile client is based on Nokia S60 platform to run the application on the customer phone, when the user through the phone shown in the interface to select the corresponding function request internally, by encapsulation URL to the server process. The phone installed on English learning system also encapsulates some business logic function. Background management system is mainly to the operation of the database server. Application is running on the server, which encapsulates the system design, all mobile phones in the working process of the client application requests to be sent as well as relevant business logic, but also to relevant background database operations. System backed on server and receives the client after the instructions sent to come over, to run the program in the business process, after processing is completed, will be even. Process the results into the format of the mobile phone on the client side to further processing, in order to contend for the format of the further adjustment on board processing, the final show on your mobile phone.

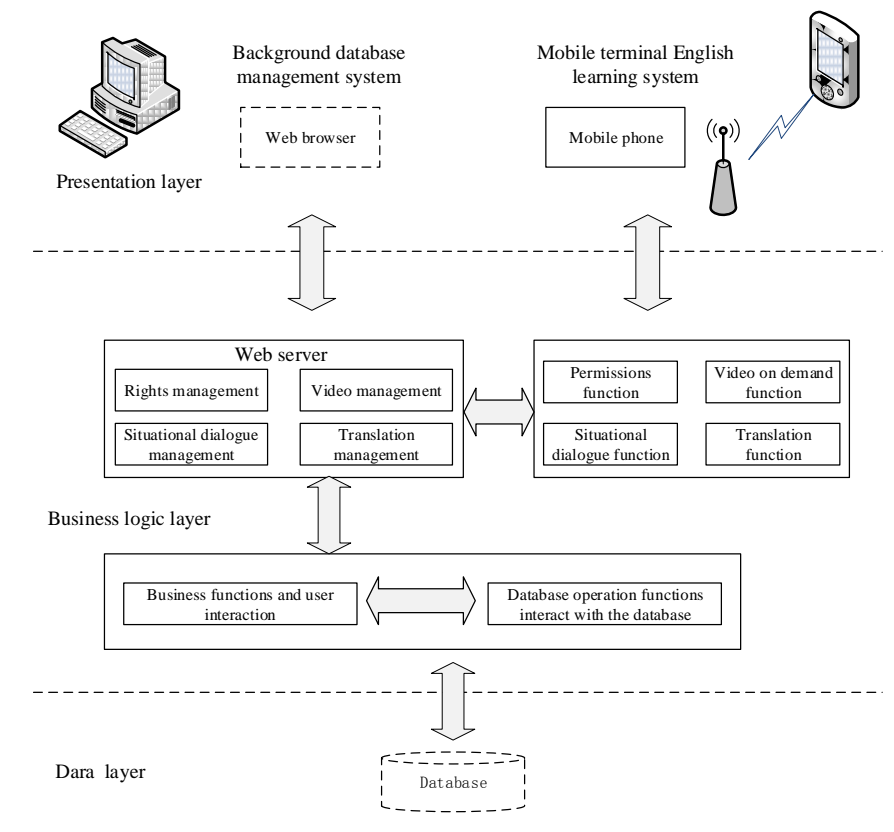

Fig. 4. Overall system structure of mobile learning English system based on $3 \mathrm{G}$ platform

\section{CONCLUSION}

Mobile learning is a kind of rapid development of new learning style. Intelligent mobile terminal equipment of the expansion and the rapid development of wireless network technology, for the purpose of the Android mobile learning system development and implementation provides the necessary theoretical and material basis. This article through the analysis of mobile learning development both at home and abroad, to understand the mobile learning related theory and basic knowledge of the Android platform software development, discussed how to on Android intelligent terminal equipment for the design and implementation of mobile learning system. With the constant innovation of mobile learning theories as well as the rapid development of science and technology, mobile learning areas become a worthy of exploration and development of emerging field. In such a background, how to optimize the mode of mobile learning applications, how to design a more perfect mobile learning system architecture, how to develop the application and the user experience more user-friendly mobile terminal software, learning all of these are worth thinking about and deeper problems. 
As the further promotion and popularization of the $3 \mathrm{G}$ technology in our country, mobile terminal platform based on the $3 \mathrm{G}$ technology has all kinds of application software with more and more development space and good prospects for development. In the field of mobile learning, all kinds of learning platform based on $3 \mathrm{G}$ technology and the software is one of the main direction of the $3 \mathrm{G}$ mobile application development. Especially in the area of English learning, with the development of China's internationalization process, there are people who need to learn English will be more and more. On English study this system in the design process, as the breakthrough, achieved based on 3G platform of an English learning system. In the process of development in the future, if you can get the education system and the $3 \mathrm{G}$ operating supplier support, as much as possible to reduce the cost of learning, and improve the quality of network communication, mobile learning will have a good development space and development prospects.

\section{REFERENCES}

[1] J. Sandberg, M. Maris, K. Geus: Computers \& Education, Vol.57 (2011) No.1, p. 1334.

[2] A. Kukulska-Hulme: Journal of Educational Technology and Society, Vol.13 (2010) No.4, p. 4.

[3] Y. Tai: Educational Technology \& Society, Vol.15 (2012) No.2, p. 220.

[4] R. Godwin-Jones: Language Learning \& Technology, Vol.15 (2011) No.2, p. 11 ..

[5] L. Hsu: Computer Assisted Language Learning, Vol.26 (2013) No.3, p. 197. 